\title{
Identity, Modality, and the Candidate Behind the Wall
}

\author{
Daniel Büring \\ Cologne University
}

\section{Introduction}

This paper reports on ongoing work on the syntax and semantics of identity constructions. In particular, I will highlight the semantic differences between what I call the pronominal identity construction (PIC) exemplified in (1), and the expletive identity construction (EIC) as shown in (2).

PIC: Pronominal Identity Construction: she/he/I...BE NP
a. She is the director.
b. She might be the director.
c. Sie ist die Regisseurin.

(2) EIC: Expletive Identity Construction: it/this BE NP
a. It is the director.
b. It might be the director.
c. Es ist die Regisseurin.

Identity constructions with modals have recently received attention in the work of Groenendijk, Stokhof and Veltman (1994, 1996, henceforth GSV) in Dynamic Modal Predicate Logic. A theoretical point made in this paper is that dynamic modal quantification over assignments as proposed by GSV yields inadequate meanings for PIC's, and is linguistically implausible in EIC's, arguing against it altogether (cf. section 4.1.).

The (tentative) conclusion will be that while PIC's represent ordinary equative copular sentences, EIC's are closely akin to cleft constructions. In fact I will present arguments in favor of analyzing clefts as expanded EIC's (or EIC's as reduced clefts if you like).

\section{Some Stunning Contrasts}

Sad News. Upon coming back to your hotel, you learn from the receptionist that one of your accomplices has had an accident down at the harbor. You are supposed to see her or him in the hospital, but in the hectic course of events the receptionist forgot to take down the name of your friend, and since there's a bunch of you, it is unclear which of your friends is the actual victim. Under such circumstances it seems appropriate for you to utter (3.a), but not (3.b), meaning, 'Maybe the person who had the accident is none other than my best friend Julius.' 
A friend of mine had an accident.

a. Es könnte mein bester Freund sein.

a. It might be my best friend.

b. \# Er könnte mein bester Freund sein.

b. \# He might be my best friend.

Herzblatt. For something more fun, suppose I participate in a game show. Having talked to three female candidates without actually seeing them, I finally blindly pick one (say, candidate \#3) as my 'sweetheart', which subsequently is presented to me behind a removable wall. I know, as everybody else, that the candidates were Andrea, an architect from Berlin, Anja, a student of medicine from Frankfurt and, Sandra a seamstress from Goslar. To increase tension, the game show host may say (4.a), but hardly (4.b).

(game show host) With me behind this wall is your sweetheart.

a. $\quad$ Es könnte die Schneiderin aus Goslar sein.

a. It might be the seamstress from Goslar.

b. \# Sie könnte die Schneiderin aus Goslar sein.

b. \# She might be the seamstress from Goslar.

c. Sie könnte eine mittelalterliche Prinzessin sein (so schön ist sie).

c. She could be a medieval princess (given how beautiful she is).

Note, too, at this point that his typical game show host charm might also allow him to say (4.c); I will come back to this below (the German modal könnte is the translation for both might and could).

Reflections on Fate and Chance (still game show). At the same show we might imagine a philosopher game show host, who would perhaps say (5.b).

(5) With me behind this wall is tonight's winner.

a. $\quad$ Es hätte auch die Verliererin sein können.

a. It could just as well have been the loser.

b. Sie hätte auch die Verliererin sein können.

b. She could just as well have been the loser.

Suppose, he said (5.a) instead, then that doesn't seem to be a reflection about the course of life, but a reflection about possible different game shows, employing different rules.

An Unexpected Visitor. This is a short one: Hearing a knock on the door, my mother says (6.a), but surely not (6.b).

(6) A man is at the door./Ein Mann steht vor der Tür.

a. Es könnte Herr Neson sein. a. It might be Mr Neson.

b. \# Er könnte Herr Neson sein. b. \# He might be Mr Neson. 
Homo Faber vs. the Monk. Imagine in your holidays you see an elderly man kissing a young woman. With a shudder of disgust (or jealousy?) you say (7.a). Max Frisch, a famous writer who happens to be in the same group as you, but knows more about the man's background even says (7.b).

That old guy just kissed this woman.

a. Dabei könnte sie seine Tochter sein!

a. $\quad$ She could be his daughter, though!

b. Dabei könnte es seine Tochter sein!

b. It could be his daughter, though!

It seems that in saying (7.b), Frisch presupposes that that man actually has a daughter and that there's a serious chance that his daughter is noone other than the woman that was kissed. For all you know, the guy may be a monk who fell for female charmes for the very first time, and, evidently with someone below his own age group.

\section{Towards an Explanation}

Before turning to the actual analysis I want to propose, let me clarify the commonalities in all the scenarios considered in the last section. In each case we are dealing with a situation in which the actual identity of someone mentioned in the linguistic context is unclear. Thus the speaker in (3), in using the indefinite a friend of mine does not actually know which person had the accident. Similarly with the referent of the someone knocking at the door, as with the identity of 'this woman' (I'll come back to the game show cases after the commercials).

If we conceive of a speaker's information state $s$, i.e. her factual knowledge, as a set of worlds, i.e. those worlds which according to the speaker could well be the real world, then the situations above have in common that in different worlds in $s$, different individuals are the friend who had an accident, the man at the door, or the woman kissed. If you prefer to think that an information state $s$ is a set of world--assignment pairs (so called possibilities), in which each world again is a candidate for the real world and the assignment tied to it reflects a hypothesis about the identity of discourse referents mentioned so far, the situations above are characterized by the fact that not all assignments in (pairs in) $s$ assign the same individual to the expression used to refer to the friend, the stranger, and the woman, respectively.

But what is really puzzling about the examples in section 1.2 is our intuition that while EIC's like it could be my best friend really do express this uncertainty w.r.t. to the referent of the NP, PIC's don't. To the contrary, the reason why he might be my best friend $(=(3 . \mathrm{b})$ ) sounds odd is precisely that it seems to make a statement about a particular person rather than about the concept 'the friend of mine who had an accident'. Looking at the game show cases, it should be noted that the game show host speaks from the perspective of the candidate: 'Given what you -- the candidate -- knows, it might be the 
seamstress from Goslar who is standing here with me'. But again, using the PIC as in (4.b) (she might be the seamstress from Goslar), he would seem to say instead: 'Given what you know, Andrea (who is standing behind this wall) could be the seamstress from Goslar', which, evidently, is not the case. Even the candidate knows that Andrea is the architect from Berlin. He doesn't think Andrea could be a seamstress, or Anja an architect, or Sandra a student of medicine. He just doesn't know who's behind the wall.

\subsection{PICs as plain 'de re' statements}

Consider again (3), repeated here in (8), with its dynamic logic translation (8.a). Importantly, the existential quantifier introduced by the indefinite $a$ friend of mine does not have scope over the entire formula. By the point its scope ends (the closing bracket) it has done the following: Out of an initial information state $s$ it has collected all those possibilities $\langle w, g\rangle \in s$ in which $g(x)$ is a friend of mine who had an accident in $w$. This is formally spelled out in the definitions in (8.b) through (8.d). ${ }^{1}$

A friend of mine $\mathrm{x}_{\mathrm{x}}$ had an accident. \# $\mathrm{He}_{\mathrm{x}}$ might be my best friend.

a. $\quad \exists x[f-o-m(x) \&$ had-acc(x)] \& $\diamond$ best-f-o-m(x)

b. $\quad s\left[\mathrm{P}\left(\mathrm{t}_{1}, \ldots, \mathrm{t}_{\mathrm{n}}\right)\right]=\left\{\mathrm{i} \in \mathrm{s}\left|<\mathrm{i}\left(\mathrm{t}_{1}\right), \ldots, \mathrm{i}\left(\mathrm{t}_{\mathrm{n}}\right)\right\rangle \in \mathrm{i}(\mathrm{P})\right\}$

c. $\quad s[\Phi \& \psi]=s[\Phi][\psi]$

d. $\quad s[\exists x \Phi]=\cup_{d \in D}(s[x / d][\Phi])$

d. $\quad s[x / d]=\left\{<w, g>\mid \exists g^{\prime}\left[<w, g^{\prime}>\in s \& g^{\prime}\right.\right.$ is identical to $g$ except that $\left.\mathrm{g}^{\prime}(\mathrm{x})=\mathrm{d}\right\}$ (defined iff $\mathrm{x} \notin \operatorname{dom}(\mathrm{g})$ )

NB: $\mathrm{i}(\alpha)$, with $\mathrm{i}=\langle\mathrm{w}, \mathrm{g}\rangle$ abbreviates $\mathrm{f}(\alpha)(\mathrm{w})$, if $\alpha$ is a constant, or $\mathrm{g}(\alpha)$, if $\alpha$ is a variable.

Importantly, due to my ignorance as to who actually had the accident, $g(x)$ and $g^{\prime}(x)$ could be different individuals even for two $\langle w, g\rangle,\left\langle w^{\prime}, g^{\prime}\right\rangle \in s$.

Let us assume for concreteness that there are three friends of mine who each might have been involved in the accident, Julius (my best friend), Lionel, and Rufus. Accordingly, (9.a) through (9.c) are elements of my information state $s$ (of course each of those stand for a large set of possibilities that differ in (irrelevant aspects of) $w$, though not in $g$ ).

$$
\begin{aligned}
& \text { a. } \quad<\mathrm{w}, \mathrm{g}>: \mathrm{g}(x)=\text { Julius, and Julius had the accident in } w \\
& \text { b. } \quad<\mathrm{w}^{\prime}, \mathrm{g}^{\prime}>: \mathrm{g}^{\prime}(x)=\text { Lionel, and Lionel had the accident in } w^{\prime} \\
& \text { c. } \quad<\mathrm{w}^{\prime \prime}, \mathrm{g}^{\prime \prime}>: \mathrm{g}^{\prime \prime}(x)=\text { Rufus, and Rufus had the accident in } w^{\prime \prime}
\end{aligned}
$$

The question is now how to interpret the modal. Evidently, the modal in (8.a) is interpreted as epistemic (given what the speaker knows), and, as we just saw, the speaker's knowledge is appropriately modelled as a set of possibilities. Pretending that might/could expresses existential quantification over possibilities, does $s$ [ $\diamond$ my-best-friend $(x)]$ say (10.a) or (10.b)? In other words, does it quantify over world-assignment pairs, or over worlds only? 
(10) a. keep all possibilities in $s$, iff according to some possibility $\left.<w^{*}, g^{*}\right\rangle \in s, g^{*}(x)$ is my best friend in $w^{*}$

b. retain only those possibilities $\left\langle w^{*}, g^{*}\right\rangle \in s$ with some $\left\langle w^{\prime}, g^{\prime}\right\rangle$ $\in s$ such that $g^{\prime}(x)=g^{*}(x)$ and $g^{*}(x)$ is my best friend in $w^{\prime}$

I will now show that (10.a) is incorrect and (10.b) is correct. This argument is somewhat involved, for remember that we want to explain the oddness of sentence (8) in the scenario describe above. Accordingly, the right meaning for the modal is the one on which something about (8.a) is wrong. So I will show that i) Negative Argument: (10.a) predicts that the speaker can felicitously utter he could be my best friend in the circumstances described (i.e. (9)); since this is empirically incorrect, so is (10.a). ii) Positive Argument: (10.b) predicts that the speaker cannot felicitously utter the sentence (because she would violate the Maxim of Quality) in doing so; this is empirically correct, lending evidence to (10.b)

The Maxim of Quality requires the speaker to say things she believes to be true. In other words, the speaker's knowledge (her information state $s$ ) must entail the meaning of $\psi$. Put the other way around, $\psi$ should not add knowledge to $s$, i.e. updating the speaker's information state $s$ with $\psi$ should yield $s$ again, not a subset of $s$.

(11) Quality:

Sentence $\psi$ can felicitously be uttered by a speaker iff the speaker's informations state $s$ entails the truth of $\psi$, that is, iff $s$ supports $\psi .^{2}$

Suppose (10.a) was the right definition. Given the information state $s$ sketched in (9) above, (10.a) is clearly met by possibilities of the type (9.a) (since in all those $w$, Julius is my best friend). Note that due to (10.a) we are entitled to keep all possibilities in $s$ (including those of type (9.b) and (9.c)) in this situation. A formula of this type is often called a test; it either leaves the information state or leads to the absurd state straightaway.

Given that according to (10.a), (8.a) is a test, and that $s$ as schematized in (9) meets this test, $s$ supports (8.a), so (8) should be felicitous for someone to utter who has the information sketched in (9). But it is not, concluding (i).

Consider now (10.b). First note that (10.b) may reduce an information state rather than just test it (it is a so-called eliminative update). Does it eliminate possibilities out of (9)? Evidently, I know who my best friend is, i.e. for all $\langle w, g\rangle \in s, f(m y$-best-friend')( $w)=$ Julius. Hence, possibilities of the type (9.a) will survive after updating with $\diamond$ my-best-friend $(x)$. But those of type (9.b) and (9.c) vanish. So $s[(8 . a)] \neq s$ (it doesnt even subsist in $s[(8 . a)])$. Therefore, (11), Quality, is violated in (8). Since this is what we want, we assume that (10.b) is correct; this concludes the positive argument (ii). ${ }^{3}$ The definition in (12.a) gives a dynamic logic rendering of (10.b), the one I propose to adopt.

$$
\begin{aligned}
& \text { a. } \quad s[\diamond \Phi]=\left\{<w, g>\mid \exists w^{\prime}, g^{\prime}, g^{\prime \prime}\left[<w^{\prime}, g^{\prime \prime}>\in s^{\prime} \& g \subseteq g^{\prime} \&\right.\right. \\
& \left.\left.<w^{\prime}, g^{\prime}>\in s[\Phi]\right]\right\}
\end{aligned}
$$




$$
\text { b. } \quad \underset{\mathrm{s}\left[\diamond_{\mathrm{BG}} \Phi\right]}{\in \mathrm{s}[\Phi]]\}}=\left\{\langle w, g\rangle \mid \exists w^{\prime}, \mathrm{g}^{\prime}\left[w^{\prime} \in \mathrm{BG}(\mathrm{w}) \& \mathrm{~g} \subseteq \mathrm{g}^{\prime} \&<\mathrm{w}^{\prime}, \mathrm{g}^{\prime}\right\rangle\right.
$$

(12.b) basically expresses the same idea, but takes into consideration that modals can be used non-epistemically. Upon reflection, a definition along the lines of (10.a) automatically equates the modal background with the information state. This is evidently inaccurate, because, as just said, modals might be evaluated w.r.t. non-epistemic backgrounds (see Kratzer 1984 for fundamental discussion). The idea behind (12.b) then is that in every $\langle w, g\rangle, B G(w)$ is the set of worlds which make up the modal background in $w$.

Let us return to the game show with that in mind. Take the odd example (13.a) first, translates as in (13.b) with the assumed circumstantial background in (13.c).

(13) a. With me behind the wall is your sweetheart. \# She might be the seamstress from Goslar.

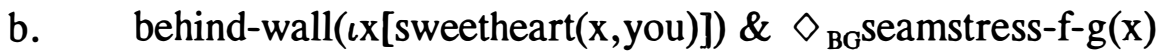

c. $\quad \mathrm{BG}(\mathrm{w})=$ worlds according to what the candidate knows in $\mathrm{w}$

Note again that $\diamond_{B G}$ does not affect the value of $g(x)$ at all. If the game show host knows that Anja is standing behind the wall, (13.a) would mean that the candidate considers it possible that Anja is the seamstress from Goslar -- contrary to fact. Even if the game show host did not know whether Anja or Andrea are standing behind the wall, (13.a) would still say that either Anja is standing behind the wall and the candidate considers it possible that Anja is the seamstress, or Andrea is standing there and the candidate thinks Andrea might be the seamstress. But again, the candidate knows that Andrea is the seamstress and Anja the to-be doctor, so (13.a) is just not appropriate. Finally, if the game show host knows it's Sandra (the seamstress) behind the wall, he asserts that Sandra, according to the speaker's knowledge, could be the seamstress from Goslar, which is not literally false, but infelicitous, given that the candidate knows she is.

Contrast this with (14). Here again the background is not a realistic one, but rather something like (14.b). So whoever the game show host knows or believes to know to be standing there is said to meet the medieval princess criteria in at least some $w^{\prime} \in B G(w)$. Nothing's odd about this, and the PIC is felicitous.

(14) a. [...] She could be a medieval Princess.

b. $\quad \mathrm{BG}(\mathrm{w})=$ worlds in which medieval princesses exist and accord to whatever criteria we associate with medieval princesses in $\mathrm{w}$

(15) a. [...] She could just as well have been the loser.

b. $\quad B G(w)=$ worlds in which the rules of the game are as in $w$, but the actual course of the game has been different

Reconsider (15) now. Given what we have said so far it plainly says that the actual person behind this wall (in $w$ ) could have lost the game in some other 
world $w^{\prime} \in B G(w)$, the latter set defined by some notion of similarity to $w$. Again, this seems a perfectly natural thing to say, so we predict the PIC to be well-formed.

Now, finally, for Mr Neson. Assuming that $f\left(M r-N e s o n^{\prime}\right)(w)$ is the same individual in all worlds $w,(16 . \mathrm{a})$ is completely parallel to case (8.a) above. However, while it seems unlikely for a speaker to be unclear about the identity of her best friend, it seems less impossible to interpret the name $\mathrm{Mr} N$ Non as a non-rigid designator, i.e. as a contingent individual concept. Accordingly, (16.b) -- with the stress pattern indicated -- sounds much better than (16.a). The reason is that this time it is not the assignment-dependent reference of he which is unclear, but the world-dependent reference of Mr Neson.

(16) a. Someone's knocking at the door. \# He could be Mr Neson.

b. HE could be Mr Neson.

The general schema of PIC sentences, then, is given in (17).

$$
\text { he } e_{x} \text { might be } P \text { : for all }<w, g>\in s, g(x) \text { is } P \text { in some } w^{\prime} \in B G(w)
$$

In the special case of epistemic backgrounds, $B G(w)$ is (roughly) $\left\{w^{\prime} \mid \exists g:\left\langle w^{\prime}, g\right\rangle \in s\right\}$ for all $w$ in $s$. Yet, we have clearly seen that modals seem to regard the second, worldly quantification, not the first one. Once we assume this, the data around PIC's follow.

\subsection{EIC's as 'Reduced Clefts'}

Let us now turn to EIC's. Recall from the contrasting pairs in 1.1. above that the EIC seems appropriate in those cases where the PIC is not, namely those cases in which the modal seems to express quantification over assignment- rather than world-possibilities.

There are two basic ways to capture this: Either we allow for two different ways to treat assignments in modal constructions (roughly: ignore them in PIC's but bind them in EIC's) or we assume that the apparent quantification over assignments is really due to quantification over worlds (by the modal) in the EIC's. It is the latter option I want to argue for here. The intuition I'd like to elaborate on is that a sentence like (18.a) in the context given above expresses the same proposition as that in (18.b), predicate logically rendered in (18.c).
a. It could be the seamstress from Goslar.
b. It could be the seamstress from Goslar, who is standing behind the wall.
c. $\quad \exists x[\operatorname{sfG}(x) \& \forall y[\operatorname{sfG}(x) \rightarrow x=y] \& \diamond x=\iota y[$ behind-wall $(y)]]$

On a pre-theoretical level it should be evident that all the EIC examples from above lend themselves to such an analogy: 
(19) a. It could be my best friend, who had an accident.

b. It could be the seamstress from Goslar, who is standing behind this wall.

c. It could as well have been the loser, who is standing behind this wall.

d. It could be Mr Neson, who is knocking on the door.

Does that work formally as well? Yes. To see this, take again (19.a) in the scenario schematized in (9), i.e. the speaker does not know whether Julius (his best friend), Lionel or Rufus had the accident; the three possibilities are represented by the three worlds--assignment pairs $\langle w, g\rangle,,\left\langle w^{\prime}, g^{\prime}\right\rangle$ and $\left\langle w^{\prime \prime}, g^{\prime \prime}\right\rangle$, respectively. The representation of the sentence is given in (20).

$\exists x\left[\right.$ friend(x) \& $\forall y[$ as-good-a-friend-as $(x, y) \rightarrow x=y] \& \diamond_{\mathrm{BG}} \mathrm{x}=\iota \mathrm{y}[\mathrm{had}-$ accident $(\mathrm{y})]]$

Let's zoom in right behind the \&-sign. $\langle w, t\rangle$ survives updating with $\diamond_{B C} x=\iota y$ [had-accident $\left.(y)\right]$ iff in some $w^{*} \in B G(w), g(x)$ (alias Julius) had an accident in $w^{*}$ (I ignore the uniqueness issue for the time being). Turning now to $\left\langle w^{\prime}, g^{\prime}\right\rangle$, absolutely nothing changes, for $g^{\prime}(x)$ is again Julius (the best friend), and $B G\left(w^{\prime}\right)$ will cum grano salis equal $B G(w)$. Likewise, $g^{\prime \prime}(x)$ is Julius, so the same reasoning applies. In that respect, the fact that the identity of the person who has had an accident is unclear, remains irrelevant, it seems. However, note that $\diamond_{B C} x=\iota y$ [had-accident(y)]] will be uninformative w.r.t. $B G$ if $\iota y[$ had-accident(y)] were a constant function in $B G$.

Summing up, assuming that EIC's literally contain a description (or an individual concept for that matter) within the scope of the modal, combined with the assumption that the modal quantifies over worlds (though not assignments) readily captures the semantics of the EIC. But how do I get the description in EIC's? My proposal is that there is an empty category in the predicate position of EIC's which is interpreted as description in intenso. In the next section I will become more precise about the syntax of the construction.

\section{More on EIC's}

\subsection{The Syntax of EIC's}

Given that EIC's are special instances of copular sentences, it seems worthwhile to ask to which argument in a 'regular' copular construction the NP in EIC's corresponds (and, accordingly, what the position and function of the expletive is). I will refer to the NPs in a regular copular sentence like Andrea is an actress as the subject and the predicate NP, respectively.

First note that the NP in EIC's possesses clear subject properties. The verb agrees with it (21), and it is questioned by wer (who) rather than was (22), both of which properties are characteristic of copular subjects, rather than 
predicate NPs ((23) and (24)).

(21) Es sind/*ist die orthopädischen Strümpfe. it are $/ *^{*}$ is the orthopaedic stockings

(22) Jemand sitzt im Schrank. Wer/\#Was kann es sein? someone sits in-the closet - who/\#what can it be

(23) Die orthopädischen Strümpfe sind/*ist ein Problem. the orthopaedic stockings are/*is a problem

(24) Peter ist so ein arroganter Idiot.

Peter is such an arrogant idiot
a. Was/\#Wer ist Peter? what/\#who is Peter
b. Wer/\#Was ist so ein arroganter Idiot? who/\#what is such an arrogant idiot

Furthermore, the NP in EIC's (and clefts) may, at least to a certain extend, be quantificational, which is not possible for predicate NPs e.g. in PIC's.

(25) The speaker mentioned a number of languages that show this construction.

Tatsächlich sind es/*sie fast alle europäischen Sprachen (, die diese Konstruktion aufweisen)

'In fact, it is/*they are almost all European languages (who have this construction)'

But if the NP is the subject, what would the expletive be? Clearly the es is not a mere 'Vorfeld' expletive, since we find it in post-verbal position as well, and it is obligatory. ...weil *(es) die orthopädischen Strümpfe sind.

As a second guess, one might suspect that it is an object pronoun (there is no case distinction in the neuter paradigm between nominative and accusative). However, as is well known, only subject es is possible in clause initial position in German, while an object pronoun in that position has to be in the strong form, das. The same effect shows up in copular sentences. While the predicative AP in (27) can in principle be taken up by either weak es or strong das, only the latter is possible if the pro-form shows up in clause initial position.

(27) Guildo ist nicht so besonders attraktiv.

Guildo is not so particularly attractive
a. Aber seine Band ist es.
but his band is it
b. Das ist dafür seine Band. the-NEUT is instead his band


c. * Es ist dafür seine Band.

it is instead his band 'Instead his band is.'

The generalization then is that pronouns in object or predicate XP function can only occur in the initial position in their strong form. In contrast we find the weak es as the initial constituent in EIC's, strongly suggesting that it does not go proxy for the predicative NP (thanks to Hubert Haider,p.c., for pointing this out to me).

The same conclusion suggest itself from the data in (28). If accented, the NP in EIC's can show up either clause initially or in the 'Mittelfeld'. Thus, both (28.a) and (28.a') are appropriate answers to the question Who is it? However, if the NP is contextually given, as in the question Who is it? Guildo Horn?, it is deaccented and can only show up post-verbally ((28.b) vs. (28.b'). Again this is typical for the behavior of objects and predicative NPs, which can be preposed only if accented.

Who is it? (Guildo Horn?)
a. Es ist Guildo HORN. it is G.H.
b. Es IST Guildo Horn
a. Guildo HORN ist es.
G.H. is it
b. \# Guildo Horn IST es.

So generally, the es behaves like a typical subject (initial position in its weak, unstressed form), while the NP doesn't (initial position only if stressed).

Finally, coordination data show that the NP and the verb be form a constituent to the exclusion of the es (29.a). Comparing this to ordinary copular sentences, this is again typical for predicate NPs, as shown in (29.b), but not for subjects, cf. (29.b).

(29) Sie behaupten,.../They claim...

a. $\quad .$. daß es $\{$ [eine Frau sein muß] und [keinesfalls ein Mann sein darf]\}.

'...that it must be woman and may not be a man.'

b. $\quad$...daß Hans $\{[$ Hamlet sein muß], und [keinesfalls Rosenkranz sein will]\}.

c. * ...daß Hamlet [[HANS sein muß], und [keinesfalls FRITZ sein kann]\}.

'...that Hamlet must be Hans, and may not be Fritz.'

What can we make of this apparently contradictory evidence? I'd like to suggest that the NP is in fact VP internal at s-structure, explaining the coordination facts as well as the fact that it cannot be in initial position if unaccented (the idea being that objects can be moved to that position only if especially marked as focus or topic, whereas subjects go there as a default or are even base generated there). At the same time, the expletive es occupies the canonical subject position SpecI, making it a default for the clause initial position.

Crucially, however, the NP does not correspond to the predicate nominal 
in regular copular sentences, but to the subject. Its position is the VP internal subject position SpecV. The canonical predicate nominal/object position is occupied by an empty element interpreted as a definite description, as claimed in the last section. The structure for EIC's in comparison to that of an ordinary copular sentence is thus as in (30).

$\begin{array}{rllll}\mathrm{C}^{\circ} & \text { SpecI } & \text { SpecV } & \text { PredNP } & \text { V } \\ \text { weil } & \text { es } & \text { Hans } & \text { EC } & \text { ist } \\ & \text { Hans } & t_{\text {Hans }} & \text { ein Schauspieler } & \text { ist }\end{array}$

To account for the agreement we could assume that the verb regularly agrees with SpecV rather than SpecI in German (which would in all 'normal' cases be the trace of the element in SpecI anyway). An alternative might be to assume some kind of chain formation between the NP and the expletive, e.g. coindexation or LF-replacement by movement.

\subsection{EIC's as the Source for Clefts}

What is the relation between EIC's and full clefts? Note that EIC's and clefts occur with the very same set of elements, or, put the other way around, disallow the same elements. For a distributional fact, PPs and APs are possible in regular copular sentences (including PIC's) as shown in (31.a), but banned from expletive copular constructions with or without a relative clause (31.b).

(31) A candidate is standing behind the wall.

a. Sie ist aus Goslar/nervös. she is from Goslar/nervous

b. * Es ist aus Goslar/nervös (,was/die sie ist). it is from Goslar/nervous (what/who she is)

Likewise, the NP in both clefts and EIC's must not be predicative (this was already implicit in the structure assumed in the last subsection). So if the game show candidate, instead of guessing who's behind the wall, is to guess the profession of a particular person, PIC's are fine, while EIC's aren't. As shown in (32.b), adding a relative clause to form a full cleft does not change things for the better.

(32) Geld oder Liebe (another game show): What do you think is Luise's hobby? Is she a break dancer, a painter, or a nude photographer?

a. Sie könnte eine Aktfotografin sein. she could a nude-photographer be

b. \# Es könnte eine Aktfotografin sein (was/die sie ist). it could a nude-photographer be (what/who she is)

Third, it is worth noting that both clefts and EIC's are restricted to the copular $b e$, cf. (33) (of course, (33.b) without the relative clause would be grammatical 
as a PIC, i.e. with sie/she instead of es/it).

(33) A woman is sitting in the outer office.

a. Es könnte deine zukünftige Mitarbeiterin sein (die...).

a. It could be your future assistant (who is ...)

b. * Es könnte deine Mitarbeiterin werden (die im Vorzimmer sitzt).

b. * It could become your assistant (who is sitting in the outer office).

It is beyond the scope of this article to account for all the restrictions on EIC's and clefts discussed in this subsection. My conclusion is just that clefts and EIC's in German are one and the same construction. For concreteness' sake I assume that the relative in a cleft binds the VP-internal variable. Put the other way around, while the variable is free, hence to be contextually assigned its value, in EIC's, it is linguistically controlled by the relative clause in full clefts. ${ }^{4}$

In all the cases looked at so far, the descriptive content of the empty predicate NP could actually be derived from the linguistic context, i.e. from a preceding indefinite or demonstrative. I would like to point out, however, that the choice of value for that variable is just generally context dependent, consider e.g. (34).

(34) (upon hearing a bird tweet) It was the nightingale, and not the lark.

Furthermore, even in cases where there is a potential linguistic antecedent, the choice for the predicate variable is rather free.

(35) I think I met your brother yesterday. It might also have been your cousin.

It seems natural to assume that the predicate in the EIC in (35) is (the one) who I met yesterday rather than (the one) I mistook for your brother. So it seems as if quite arbitrary bits of co-text are readily available for constructing the value of the predicate variable.

\section{Alternatives}

\subsection{Dynamic Modals (Groenendijk, Stokhof \& Veltmann 1994, 1996)}

As said above, identity statements of the EIC-type can be conceived of either as statements about the referent assigned to a given discourse referent, or as statements about the referent matching a certain description.

(36) A friend of mine $e_{x}$ had an accident. It might be my best friend.

a. in some possibilities $\langle w, g\rangle, g(x)$ is my best friend in $w$

b. in some (epistemically accessible) worlds $w$, my best friend in $w$ is the person who had an accident in $w$ 
While I have argued for the latter perspective in this paper, Groenendijk, Stokhof and Veltman (1994, 1996; GSV) defend the first. Part and parcel of their implementation are two assumptions: i) modals, e.g. the logical operator $\diamond$, quantify over world--assignment pairs (as shown in (37.a)); ii) EIC's contain a free variable of type $\langle e>$. Accordingly, (36) is translated as in (37.b).

$$
\begin{array}{ll}
\text { a. } & s[\diamond \Phi]=\{i \in s \mid s[\Phi] \neq \varnothing\} \\
\text { b. } & \exists x[f-o-m(x) \& \text { had-acc(x)]\& } \diamond \text { best-f-o-m(x) }
\end{array}
$$

As pointed out, this solution is semantically equivalent to the one advocated here. My basic objection concerns premise ii) from above: It is precisely the construction without a pronoun which has the semantics rendered by (37.b), while that with a pronoun -- the PIC -- doesn't, as we have seen above. GSV seem to gloss over the difference between PIC's and EIC's in their paper, suggesting that PIC's have the reading under debate (though they keep using EIC's in illustrating their point). Taking the linguistic data seriously, however, would force us to assume that there are in fact two types of modal quantification, one with and the other without access to assignments. The initial virtue of the GSV analysis, namely that the semantics is a natural result of the interplay between pronouns (translated as variables) and dynamic modals is thus gone. Put in other words, the data do not seem to argue in favor of the kind of assignmentsensitive modality GSV propose in natural language.

\subsection{It as a Descriptive Pronoun}

A solution that is somehow in between mine and the one discussed in the previous subsection would be to assume that the it/es in the EIC is a special pronoun, i.e. it denotes a description or an individual concept. That is, while 'ordinary' pronouns like he/she/they denote rigid w.r.t. worlds, are thus unaffected by modal quantification, the it pronoun found in EIC's responds to modality (a version of this solution could be implemented along the lines of van Rooy 1997, who assumes a dynamic logic with property variables, treating pronouns -- at least in some cases -- as definite articles operating on a familiar property variable; however, van Rooy just as GSV overlooks the difference between PIC's and EIC's).

Independent of technical details, my objections to this kind of solution is: The description found in EIC's just doesn't behave as if it were situated in the position of the it. Put differently, it is rarely possible to replace the it by a definite description in EIC's, as it should be for an E-type pronoun. For example, while an EIC subject cannot control a PRO subject in another, infinitival EIC (38.a), this is possible for definite subject NPs in ordinary copular sentences, witness (38.b). 
Someone was seen near the jailhouse.

a. * Es könnte ein Häftling sein, ohne gleich Al Capone zu sein/sein zu müssen.

'It could be a convict, without necessarily being $\mathrm{Al}$ Capone.'

b. Derjenige, der in der Nähe des Gefängnisses gesehen wurde, könnte ein Häftling sein, ohne gleich Al Capone zu sein/sein zu müssen.

'The one who was seen near the jailhouse could be a convict without necessarily being Al Capone.'

c. Es könnte ein Häftling sein, ohne daß es gleich Al Capone ist/sein muß.

'It could be a convict, but it needn't be Al Capone.'

For another, as noted before, it remains unclear why the alleged E-type pronoun is restricted to occur in be-copular sentences, cf. (33) above.

Third, in modal EIC's it is typically, if not always, the 'hidden' description (i.e. the predicate) that is interpreted within the scope of the modal, not the overt NP. Thus, as noted before, (39.a) cannot mean 'the person actually standing behind the wall could -- under different circumstances -- be the loser' (this was initially pointed out to my by Maribel Romero). As (39.b) shows, the same effect shows up in clefts, i.e. the relative clause does not seem to allow for a 'de re' reading (alias matrix index evaluation).

(39) a. It could just as well have been the loser.

b. It could just as well have been the loser, who is standing behind the wall.

c. The person standing behind the wall could just as well have been the loser.

This contrasts with subjects of ordinary copular sentences, as shown in (39.c), which can have the very reading just discussed. This pattern is predicted under the assumption that the description is incarnated as a free variable inside the VP, hence c-commanded by the modal (similar to the NP the loser in (39.c)), and that the relative clause in full clefts is anchored to that variable. Under the assumption, however, that the it is a descriptive pronoun, this behavior is completely unexpected; rather one would expect (39.a) to mean the same as (39.c).

A related forth argument is that the NP in EIC's patterns with subjects rather than predicate nominals -- among other things -- w.r.t. presuppositions. That is, while the NP his daughter used as a predicate nominal in ordinary copular sentences and PIC's does not project its presuppositions, as seen in (40.a), it does if used in EIC's and clefts, cf. (40.b). That's why we don't get the monk reading for the latter sentence.

(40) a. She/The woman he just kissed could be his daughter.

b. It could be his daughter (who he just kissed) 
This should again be the other way around if the it was the subject of the EIC and the NP functioned as the predicate NP.

\section{Appendix: On the Need for Dynamic/Descriptive/E-Type/Individual Concept Pronouns}

Finally I'd like to browse through some examples from the literature which have been take to indicate the need for decriptive pronouns or some equivalent thereof.

(41) a. My home once was in Maryland, but now it's i(Partee 1972:425)

b. My car used to be a Ford, but now it's a ToyфIanssen 1984:179)

According to the authors quoted, the it in the second clause cannot denote an individual (which would imply that a part of Maryland was now in L.A., or that my Ford somehow transformed into a Toyota), but must denote something which can depend on the temporal index, e.g. an individual concept or a full description. Though this observation is unobjectionable, note that we cannot tell from eyesight whether the examples in (41) really involve PIC's, or EIC's (from which we would expect such a behavior). The reason is of course that it -- just as its German counterpart es -- can either be an expletive or a neuter pronoun.

German turns out to be a good test case, since it shows gender agreement even with inanimate noun phrases. Thus the translation of home, Heimat is feminine and can only be picked up by a feminine pronoun, as shown in (42.a). When it comes to translating the second clause of (41.a), however, the feminine pronoun is impossible, but expletive es is called for (the same holds mutatis mutandis for the translation of (41.b) using the masculine Wagen for car).

a. Meine Heimat liegt im Ruhrpott, und ich liebe sie/*es sehr. My home $_{\text {fem }}$ is in the 'Ruhrpott', and I love her/*it very much.

b. Meine Heimat war der Ruhrpott, aber mittlerweile ist es/*sie Köln.

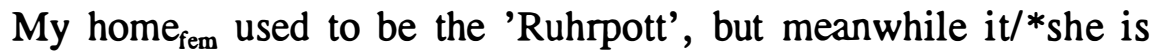
Cologne.'

This strongly suggests that were are dealing with EIC's in (41) as well, so the analysis given before carries over to these cases: It is not the it which denotes a description, but the variable in predicate NP position.

Let us now turn to cases in which no EIC analysis is possible, i.e. those involving he or she.

(43) a. Mary hasn't yet found the man she will marry. Now that she has a job in Washington, she hopesoperuliø7laet, branssen 1984:187)

b. Maria hat noch immer nicht den Mann zum heiraten gefunden. Jetzt, wo sie in Köln arbeitet, hofft sie, daß sie ihn treffen wird. 
Apparently, him/ihn in (43) must denote the description the man she will marry, contradicting the generalization suggested. Upon closer inspection, however, things aren't that clear, for one could argue that even the man she will marry is used 'referentially'. The idea would be that the speaker thinks of the man of Andrea's dreams as being out there, though undiscovered yet.

This is not a far-fetched story, for if we construct an example in which such a strategy is not available, the PIC becomes impossible again, cf. (44).

(44) Bis letzte Woche war Andrea Sawatzki die Frau, die er heiraten wollte, aber jetzt ist es/\#sie eine andere.

'Until recently, A.S. was the woman he wanted to marry, but now it/\#she is someone else.'

Note that an EIC is possible, but the PIC isn't (unless I want to say that Andrea has become a different person, of course). This is again as expected, given that here the she would unambiguously have to denote the concept 'the woman of my dreams'.

A problematic case in English is (45.a).

(45) a. This year the president is a Republican. Next year he will be a Democrat.

b. Im Moment ist der Kanzler ein Christdemokrat, aber ab Herbst wird es/*er hoffentlich ein Sozialdemokrat sein.

I don't have much to say about (45.a), except that it's German equivalent (45.b) is awkward, unless transformed into an EIC (the only reading the PIC has is one where the present chancellor actually changes sides -- an unlikely scenario to say the least). Unless further subtleties are discovered, it seems as though there is a real micro-parameter lurking here.

In general it should be stressed that more research is needed. In particular I do not want to claim that there are no descriptive pronouns in natural language, see e.g. Neale 1991, Heim \& Kratzer 1997:11 and van Rooy 1997:ch.3 for recent arguments pro such pronouns. My more moderate claim is that we do not find them in PIC's (and don't need them in EIC's). But if that's the picture, the question arises what actually blocks them there, or, why they do not interact with modals in PIC's the way full NPs do (or the variable in EIC's for that matter).

Other questions arise as soon as we broaden the data base. For example, what is the relation between EIC's and what could be called DIC's, i.e. demonstrative expletive constructions, such as in (46)?

(46) (upon seeing a scheme in the distance)

a. That could be my best friend.

b. Das könnte mein bester Freund sein.

These behave parallel to EIC's in many respects, yet there is a clear 
demonstrative effect due to the use of that/das. But obviously, the notion of a demonstrative expletive does not make any sense. My suspicion is that a closer examination of cases like (46) will eventually lead to a revaluation of the semantic contribution of the it in EIC's as well (after all, couldn't this be the same it as in it's cold?).

Finally, as Irene Heim (p.c.) points out, there are cases in which pronouns do seem to behave like descriptions in modal environments. If mother goat knocks on the door of her hut, and the seven little goats open immediately without even asking who's there, she might say (47).

Are you crazy to open the door like this?! I could have been the wolf!

I think that not only the choice of first person but also the temporal structure of the sentence contributes to this effect; closer examination is certainly needed.

On the occasion of encountering (47), some readers might think of a whole class of resembling cases with second person pronouns, in which the addressee is actually uncertain about the intended referent of the speaker's use of you, e.g. in an utterance of You are a fool. (Stalnaker 1978; see Haas-Spohn 1991 for a recent overview and more references). It is usually assumed that in such cases (or maybe in general) the addressee is entitled to reinterpret the utterance as 'the person the speaker addresses is a fool' in order to gain a single proposition as the meaning of the utterance. This proposition is called the diagonal of the character expressed by the sentence (see again the references just mentioned). Isn't that very similar to the cases discussed in this paper? I guess it is, in that one can perhaps re-interpret an utterance of $\mathrm{He}$ is my best friend simply as 'the person the speaker intends to refer to by her use of he is her best friend', if one does not know who that particular person is. In essence one gets rid of assignment functions altogether (this is argued for by van Rooy 1997, if I understand him correctly).

But even if we assimilate the treatment of first/second and third person pronouns in this way, the lesson to be learned from the PIC--EIC-contrast seems to remain constant: Diagonalization is a viable option at the sentence level, when it comes to updating the context with the proposition expressed by the sentence. However, modals, perhaps linguistic expressions in general, do not use the diagonal of their argument's meaning. Put plainly, He could be my best friend can be interpreted using its diagonal as in 'the person the speaker intends to refer to is such that he could be speaker's best friend', but not as 'It could be that the person the speaker intends to refer to is her best friend'.

To conclude this paper, I have attempted to show that PIC's and EIC's are syntactically and -- consequently semantically -- quite different from each other. While PIC's are ordinary copular sentences with a pronominal subject, EIC's were argued to be copular sentences with an empty predicate NP, whose value is assigned from the context (EIC's) or an extraposed relative clause (clefts). A more general point is that we do not seem to find any interesting interaction between pronouns and modals, as we do between descriptions and modals. 
Accordingly the PIC--EIC contrast provides an argument against varying assignment functions in modal backgrounds, not even in epistemic ones.

\section{Endnotes}

* I'd like to thank the audiences at Sinn \& Bedeutung 1997, the Amherst semantics reading group, SALT 8 and the HCRC in Edinburgh for their help and comments, far too little of which I have been able to take into consideration in this version.

1. These definitions, in particular (8.d) are adapted from GSV (1996:188ff), though most of them are current in dynamic logics. The main difference to GSV is that I do not use pegs but directly associate variables with individuals, a point which is -- as far as I can see -- orthogonal to the issues relevant here.

For brevity, I use $\mathrm{P}(\mathrm{a})$ instead of $\mathrm{a}=\iota \mathrm{x}[\mathrm{Px}]$; $\iota$-expressions in turn are used as abbreviations for full Russellian descriptions see e.g. (20) below. 2 . Why ' $s$ supports $\psi$ ' rather than 's equals $s[\psi]$ '? Because the speaker may of course change $s$ through $\psi$ by introducing new discourse referents (=changing assignments), but she may not eliminate worlds. So what is required then, is that every world $w$ in $s$ must find itself in at least on possibility in s'. This is defined using the notion of support:

(i) $\quad s$ subsists in $s^{\prime}$ if for every $\langle w, g\rangle \in s$, there is at least one $g^{\prime}$ such that $g \subseteq g^{\prime}$ and $\left\langle w, g^{\prime}\right\rangle \in s^{\prime}$ (cf. GSV 1996:188f)

(ii) $\quad s$ supports $\psi$ iff $s[\psi]$ exists and $s$ subsists in $s[\psi]$ (GSV 1996:192)

3. Could (8) ever be felicitous by these definitions? Intuitions tend to say 'no'. Surely not as long as I know who my best friend is (see the reasoning in the last paragraph). A felicitous utterance of (8) would require that whatever $g(x)$ had an accident in some $\langle g, w\rangle \in s$ is my best friend in some other $w^{\prime}$ with $\left\langle g^{\prime}, w^{\prime}\right\rangle \in s$ as well. That is, being my best friend must at least potentially be contingent on who had the accident. And I do in fact think that if (8) has any meaning at all, this is what it says.

4. The situation is less straightforward in English, since clefts and EIC's do not behave as parallel, as pointed out to my be Caroline Heycock and Antony Kroch (p.c.) who attribute this argument to Higgins 1972.

\section{References}

Cooper, Robin (1979) 'The interpretation of pronouns'. In: Heny, F. \& H.Schnelle (eds) Selections from the Third Groningen Round Table, Syntax and Semantics 10. New York: Academic Press. 61-92.

Groenendijk, Jeroen \& Martin Stokhof \& Frank Veltmann (1994) This Might Be It. Ms. Amsterdam. 
Groenendijk, Jeroen \& Martin Stokhof \& Frank Veltmann (1996) Coreference and Modality. In: Lappin, Shalom (ed) The Handbook of Contemporary Semantic Theory. Oxford: Blackwell. 179-213.

Haas-Spohn, Ulrike (1991) Kontextveränderung. In: von Stechow, Arnim \& Dieter Wunderlich (eds) Semantics - An International Handbook of Contemporary Research. Berlin etc.: De Gruyter. 229-250.

Higgins, James (1972) The Pseudo-Cleft Construction. PhD dissertation. MIT.

Janssen, Theo M.V. (1984) 'Individual concepts are useful'. In: Landman, F. \& F.Verltman (eds) Varieties of Formal Semantics. Dordrecht: Foris. 171192.

Kratzer, Angelika (1981) The Notional Category of Modality. In: Eikmeyer, H.J. \& H. Rieser (eds) Words, Worlds, and Contexts. New Approaches in Word Semantics. Berlin: de Gruyter. 38-74.

Partee, Barbara (1972) 'Opacity, coreference and pronouns'. In: Davidson, D. \& G.Harman (eds) Semantics of Natural Language, Synthese Library 19. Dordrecht: Reidel. 415-441.

van Rooy, Robert (1997) Attitudes and Changing Contexts. PhD diss. Stuttgart University.

Stalnaker, Robert (1978) Assertion. In: Cole, Peter (ed.) Syntax \& Semantics 9: Pragmatics. New York, San Francisco, London: Academic Press. 315332. 